\title{
A CASE OF THROMBUS IN THE LEFT AURICLE SIMULATING MITRAL STENOSIS
}

\author{
BY \\ ERIC M. NANSON AND R. MILNES WALKER \\ From the Department of Surgery, University of Bristol
}

(RECEIVED FOR PUBLICATION MARCH 11, 1952)

The surgical relief of mitral stenosis is now an accepted procedure, and the results are most gratifying when performed for clear-cut cases of stenosis without regurgitation. In selecting cases suitable for operation one of the chief difficulties is to differentiate mitral regurgitation from mitral stenosis, and, where the two are associated, to decide which is the major component. Auricular fibrillation is not considered a contraindication to operation, but it does add to the hazard because thrombus may be present in a fibrillating auricle. Then at operation an embolism may be separated off from the thrombus and lodge in a peripheral artery, producing a hemiplegia in the case of the cerebral vessels, or gangrene in the case of the limb vessels.

However, clot formation is not common in an auricle which is in normal rhythm and has never been in fibrillation. Furthermore it must be uncommon for a clot to be attached in such close proximity to the mitral orifice of a normally beating left auricle that it overlies the mitral valve, thereby producing the symptoms and signs of mitral stenosis. Yet such a condition was present in the case to be described, and it caused death following an operation for exploration of the mitral valve.

\section{CASE History}

Mrs. W. D. F., aged 53 years, a housewife, was admitted to the Bristol Royal Infirmary on September 19, 1951, under the care of Dr. D. H. Davies. Three years previously she began to develop breathlessness on exertion and found she could not run to catch a bus. She had had no previous history of rheumatic disease. Six weeks before admission she had a sudden severe attack of dyspnoea while walking up a hill and had difficulty in reaching her home. Since then she had been unable to do her housework because of dyspnoea. She had several attacks of haemoptysis during an attack of bronchitis. There was no history of cardiac failure.

Examination on admission revealed a welldeveloped, cheerful woman in no distress. There were no significant findings apart from the cardio- vascular system. The apex beat was in the fifth interspace in the mid-clavicular line. The first heart sound was normal in all areas. There was a short presystolic diastolic murmur confined to the apex. The pulmonary second sound did not appear to be accentuated. Rhythm was regular at 80 per minute. Blood pressure varied between $120 / 80$ and $140 / 65$ when recorded on different days. The above findings were noted by Dr. Davies and various members of the medical staff.

However, some days later when we saw the patient in consultation to consider surgery no cardiac murmurs were audible, even after the patient had been exercised. Some two weeks later a loud diastolic murmur returned and continued up to the time of operation. An electrocardiograph on September 28 showed nodal rhythm (Fig. 1), but on October 15 a further electrocardiograph showed sinus rhythm and a normal pattern (Fig. 2).

Cardiac catheterization was performed by Dr. J. A. Cosh on November 9. The findings are shown in the Table. It will be seen that the mean pulmonary artery pressure was $36 \mathrm{~mm}$. $\mathrm{Hg}$ at rest and rose to $65 \mathrm{~mm}$. $\mathrm{Hg}$ after three minutes' exercise, and the

TABLE

Cardiac Catheterization Record of Mrs. W. D. F.

\begin{tabular}{|c|c|c|c|c|}
\hline $\begin{array}{c}\text { Site of } \\
\text { Catheter Tip }\end{array}$ & $\begin{array}{c}\text { Mean } \\
\text { Pressure } \\
(\mathrm{mm} . \mathbf{H g})\end{array}$ & $\begin{array}{c}\text { Oxygen } \\
\text { Content } \\
\text { (ml./litre) }\end{array}$ & $\begin{array}{l}\text { Oxygen } \\
\text { Capacity }\end{array}$ & $\begin{array}{c}\text { Satura- } \\
\text { tion }\end{array}$ \\
\hline 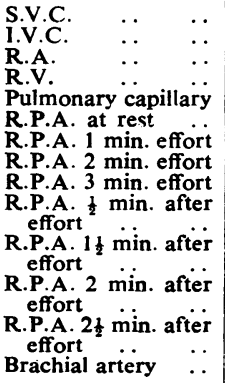 & $\begin{array}{r}3 \\
3 \\
3 \\
24 \\
24 \\
36 \\
59 \\
65 \\
67 \\
65 \\
47 \\
41 \\
36\end{array}$ & $\begin{array}{l}72 \\
67 \\
62 \\
69 \\
62\end{array}$ & $\begin{array}{c}(132) \\
(132) \\
130 \\
132 \\
129\end{array}$ & $\begin{array}{l}54 \\
50 \\
48 \\
52 \\
48\end{array}$ \\
\hline
\end{tabular}

A.V. difference at rest: $114-64=50 \mathrm{ml}$./litre. $\mathrm{O}_{2}$ consumption at rest during catheterization $=240 \mathrm{ml}$. Cardiac output at rest $=\frac{240}{50}$ $=4.8$ litres $/ \mathrm{min}$. Surface area $=1.4$. Cardiac index $=3.45$ litres 


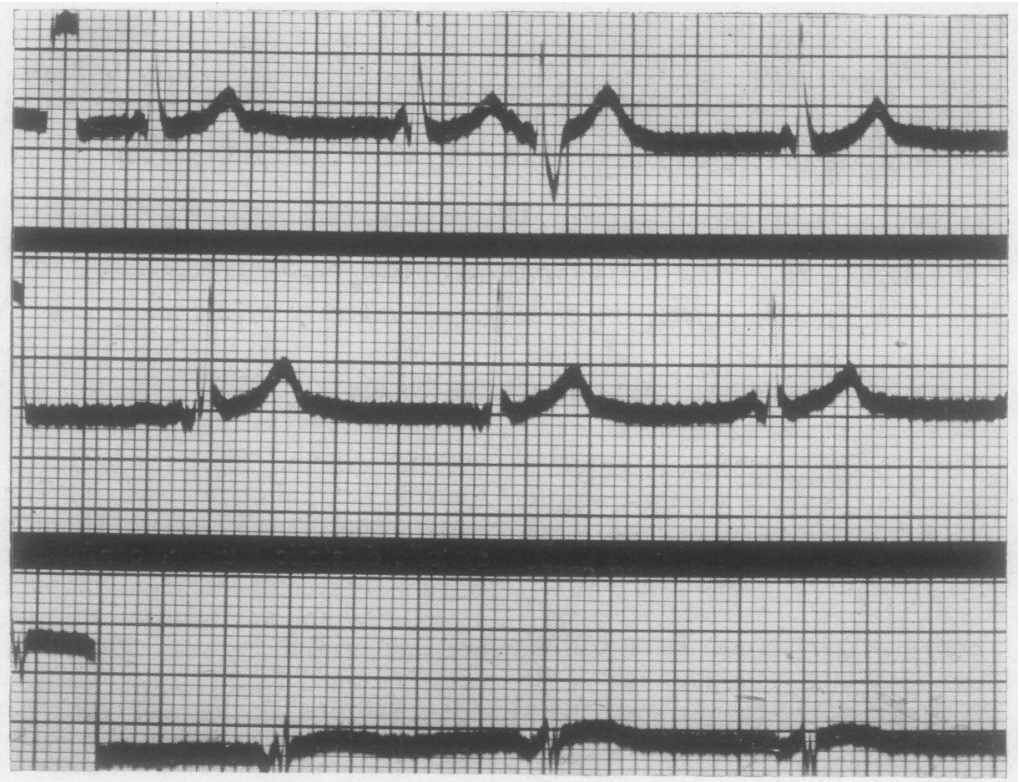

FIG. 1.-Electrocardiograph on September 28 showing nodal rhythm.

venous oxygen saturation fell to $29 \%$. The cardiac index, on the other hand, was within normal limits.

Radioscopy and radiography showed no significant increase in the size of the heart. It was thought that there was some increase in the size of the left auricle and an increased prominence of the pulmonary artery. The E.S.R. was $17 \mathrm{~mm}$./hour.

In view of the inconstancy of the diastolic murmur operation was not advised, but when an unequivocal diastolic murmur returned, and after further cardio- logical consultation, it was decided to proceed. The loud diastolic murmur and the high pulmonary arter pressure, which doubled on exercise, persuaded to that a marked mitral stenosis was present.

On November 18 a left anterior thoracotomy was performed. The pulmonary artery was tense but not enlarged, and the left auricle and auricular appendi* were of normal size and not unduly tense. These findings made us suspicious that the diagnosis was incorrect before the auricle was opened. When the

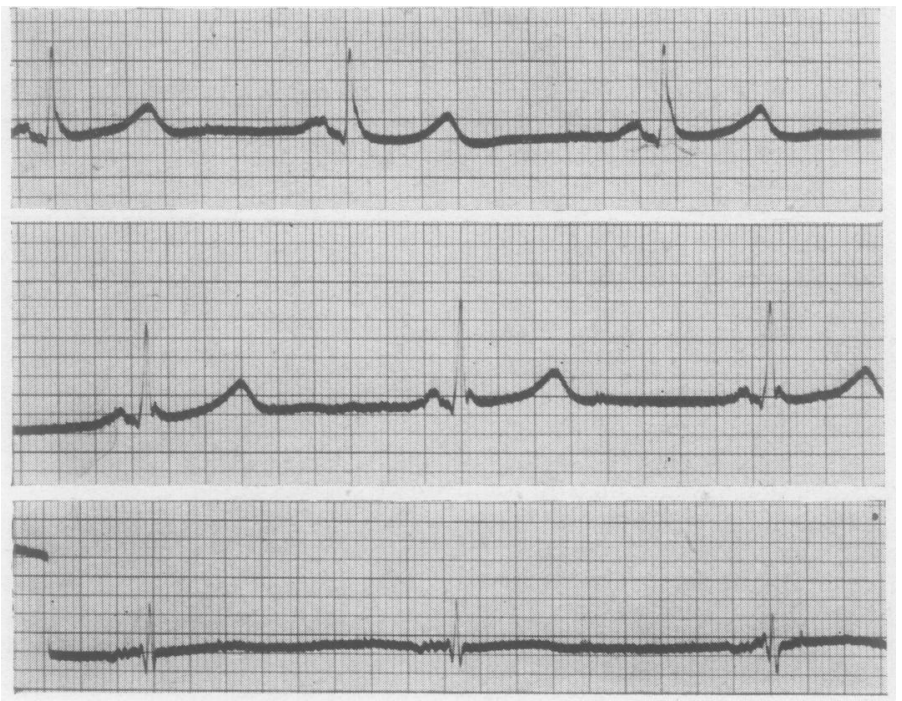

FIG. 2.-Electrocardiograph on October 15 showing return to sinus rhythm. 
finger was introduced into the left auricle a small amount of regurgitation was felt through the mitral valve. The valve admitted about one and a half fingers. The antero-lateral commissure was open right to the annulus fibrosis, but the postero-medial commissure was firmly adherent and thickened for about half of its length. This was obviously the seat of chronic rheumatic disease with some degree of pathological stenosis which, however, was not of a clinically significant degree. No clot was present in the auricular appendix and, unfortunately, none was felt by the exploring finger in the auricle itself. Accordingly the auricular appendix was amputated and closed with purse-string and mattress sutures.

Post-operatively the patient was unduly restless, and some hours after the operation had finished it was evident that she had a right-sided hemiplegia. She slowly improved over a period of seven days and then began to deteriorate and died on the eleventh postoperative day.

A necropsy was performed. This revealed infarction of the left internal capsule of the brain and of a large area of overlying cerebral cortex. There was also an embolic infarction of the right kidney of about 10 days' duration. The heart showed chronic rheumatic endocarditis, with a mild degree of mitral stenosis. There was a thrombus firmly attached to the left auricular wall just above and to the outer side of the antero-lateral commissure of the mitral valve. It did not extend out as far as the suture line of the amputated appendix. The thrombus was overlying the mitral valve, and it appeared that it would have had a ball-valve effect (Fig. 3). Sections of the thrombus where it was attached to the auricular wall showed areas of hyalinization and fibroblastic reaction and an endothelial covering, indicating its probable age to be of several weeks. Sections of the auricular wall showed no Aschoff nodules and the muscle was not hypertrophied.

In retrospect, this patient was not suffering from mitral stenosis of clinical significance, but had in fact developed a thrombus attached to the wall of the left auricle which was in normal rhythm. The thrombus had extended across the mitral

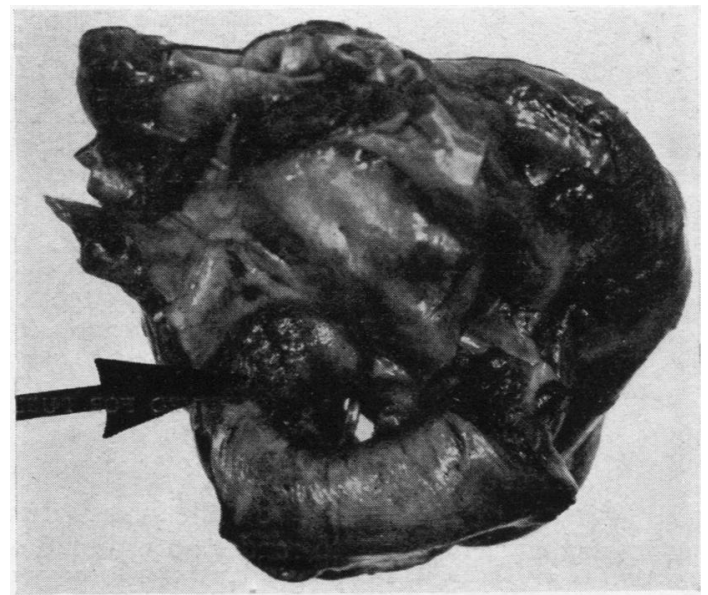

FIG. 3.-Mitral orifice from above with thrombus partly overlying it.

orifice, which was already somewhat narrowed and rigid, and thus produced the symptoms and signs of mitral stenosis of rapid onset. But the obstruction was not fixed and hence accounted for the inconstancy of the mitral diastolic murmur. When a finger was introduced into the left auricle a part of the clot, unrecognized by the operator, was broken off and produced a cerebral embolism.

The moral to be drawn from this case is that it is unwise to operate on a case of mitral stenosis which has not a clear-cut clinical history and constant physical signs.

\section{SUMMARY}

A case of thrombosis occurring in a left auricle in normal rhythm is described. The thrombus overlay the mitral orifice and produced symptoms and signs which simulated exactly those of severe mitral stenosis. At operation a portion of the clot was displaced, producing a fatal cerebral embolism. 